\title{
Selective Toll-Like Receptor Expression in Human Fetal Lung
}

\author{
JOSHUA E. PETRIKIN, ROGER GAEDIGK, J. STEVEN LEEDER, AND WILLIAM E. TRUOG \\ Department of Pediatrics [J.E.P., W.E.T.], Division of Pediatric Pharmacology and Medical Toxicology [R.G., J.S.L.], University of \\ Missouri-Kansas City School of Medicine, Kansas City, Missouri 64108
}

\begin{abstract}
Toll-like receptors (TLRs) are critical components of the innate immune system, acting as pattern recognition molecules and triggering an inflammatory response. TLR associated gene products are of interest in modulating inflammatory-related pulmonary diseases of the neonate. The ontogeny of TLR-related genes in human fetal lung has not been previously described and could elucidate additional functions and identify strategies for attenuating the effects of fetal inflammation. We examined the expression of 84 TLR-related genes on 23 human fetal lung samples from three groups with estimated ages of 60 (57-59 d), 90 (89-91 d), and 130 (117-154 d) d. By using a false detection rate algorithm, we identified 32 genes displaying developmental regulation with TLR2 having the greatest up-regulation of TLR genes (9.2-fold increase) and TLR4 unchanged. We confirmed the TLR2 up-regulation by examining an additional 133 fetal lung tissue samples with a fluorogenic polymerase chain reaction assay (TaqMan) and found an exponential best-fit curve during the study time. The best-fit curve predicts a 6.1 -fold increase from 60 to $130 \mathrm{~d}$. We conclude that TLR2 is developmentally expressed from the early pseudoglandular stage of lung development to the canalicular stage. (Pediatr Res 68: 335-338, 2010)
\end{abstract}

$\mathrm{T}_{\mathrm{s}}$ oll-like receptors (TLRs) are a critical component of the mammalian innate immune system and act as a vital trigger of inflammation in the body. Most, but not all, TLR proteins signal through a complex intracellular cascade using the MyD88 pathway. TLRs function as an inflammation switch and consequently are of interest in the study of neonatal inflammatory conditions. TLRs have been implicated in various conditions affecting newborns, including necrotizing enterocolitis (1), bronchopulmonary dysplasia (2-4), preterm birth (5), inflammatory bowel disease (6), differential response to bacterial sepsis $(7,8)$, and as mediators of the sequelae of maternal smoking (9). Although TLRs are expressed in abundance on inflammatory cells (spleen, dendritic cells, etc.) and on cells in direct contact with the external environment (pulmonary type 2 cells and intestinal enterocytes), they are also

Received December 7, 2009; accepted May 22, 2010.

Correspondence: Joshua E. Petrikin, M.D., Children's Mercy Hospitals and Clinics, Section of Neonatology, 2401 Gillham Road, Kansas City, MO 64108; e-mail: jepetrikin@cmh.edu

Supported, in part, by the Center for Infant Pulmonary Disorders, Children's Mercy Hospital and Clinics, grant NHLBI R01 HL 70560 (W.E.T.), and Children's Mercy Hospital Research Vision. The project entitled "Laboratory of Developmental Biology" was supported by grant NIH Award Number 5R24HD000836 from the Eunice Kennedy Shriver National Institute of Child Health and Human Development.

The content does not necessarily represent the official views of the Eunice Kennedy Shriver National Institute of Child Health and Human Development of the National Institutes of Health. found on other organ cells (ovary and kidney) (10) where their function is unknown.

TLR2 and TLR4 recognize LPS and peptidoglycans, respectively, providing an innate immune response against the most common pathogens involved in chorioamnionitis and neonatal sepsis/pneumonia. In utero activation of TLR4 with LPS has been shown to mature lungs and alter the septation of alveoli in fetal sheep (11). Both TLR2 and TLR4 show a several fold increase in mRNA expression in ovine and murine fetal lung from late gestation to term and continuing into adulthood (12,13). In contrast, expression in murine liver tissue is similar in fetal, newborn, and adult stages without developmental expression (12). TLR4 on nonimmune cells of murine lung preserves and maintains the lung architecture. TLR $4^{-1-}$ mice given bone marrow transfusions from wildtype mice had absence of TLR4 on the parenchymal cells, but not on inflammatory cells, and developed a gradual loss of lung elasticity and irreversible airspace enlargement (14). Thus, TLR2 and TLR4 are present on both inflammatory and noninflammatory cell lines, display developmental expression distinct from other organ systems, and have the ability to alter the structure of pulmonary tissue in murine and ovine models. However, there are no studies describing the ontogeny of TLRs on human fetal lung tissue. Elucidating the patterns of developmental expression of TLRs in human fetal lung could provide support for the interaction of TLRs in both normal and dysregulated neonatal pulmonary conditions associated with inflammation. The goals of the study are to identify developmentally regulated TLR signaling pathway genes with a focus on TLR2 and TLR4 specifically. The primary objective was to identify the developmental changes of mRNA expression in 84 genes involved in the TLR signaling pathway in human fetal lung tissue in three groups of varying estimated GA. The secondary objective was to confirm the results by quantitative real-time (RT)-PCR and to provide more detailed characterization of the relationship between TLR2 and TLR4 expression with fetal age.

\section{METHODS}

Samples. Human fetal lung tissue samples were obtained from the Laboratory of Developmental Biology, University of Washington (Seattle, WA), a National Institute of Child Health and Human Development supported tissue retrieval program. Limited information is available concerning the health status of the mothers, but tissues are from elective terminations and are presumed to be free of abnormalities or inflammation. The postmortem interval before collection and freezing was $<2 \mathrm{~h}$ for all the samples. The use

Abbreviations: ACTB, beta actin; $\boldsymbol{C}_{\boldsymbol{v}}$, cycle threshold; TLR, toll-like receptor 
of these tissues was approved by the University of Missouri-Kansas City Pediatric Health Sciences Review Board.

RNA extraction and purification. Tissues were stored at $-70^{\circ} \mathrm{C}$ before preparation. Frozen lung tissues $(20-30 \mathrm{mg})$ were homogenized and total RNA extracted according to the QIAGEN RNeasy protocol (QIAGEN, Valencia, CA) with an on-column DNase I treatment. Briefly, frozen tissue samples were placed in the provided lysis buffer and homogenized with a rotor-stator homogenizer for at least $30 \mathrm{~s}$, simultaneously disrupting and homogenizing the samples. Samples were then centrifuged for $3 \mathrm{~min}$ and the supernatant transferred to a new tube and mixed with $70 \%$ ethanol by pipetting. This mixture was applied to the provided spin column and centrifuged for $15 \mathrm{~s}$ with the flow through discarded. As per protocol, RNase free DNase I was added onto the column and incubated at room temperature for 30 min to remove all DNA contaminants efficiently. Afterward, the column was washed three times with provided buffers and the purified total RNA eluted off with two applications of RNase-free water placed directly on the column and spun through. Extracted RNA quality was assessed using the microfluidicsbased Experion RNA StdSens analysis chip/kit with the Experion-automated electrophoresis station (Bio-Rad, Hercules, CA) according to the manufacturer's protocol. Samples were chosen with an RNA quality index $>8.5$.

RNA processing and plate-array analysis. Total RNA from each sample was converted to cDNA via a reverse transcriptase reaction using the SABiosciences First Strand kit and analyzed with a commercially available TLR RT ${ }^{2}$ Profiler PCR Array (SABiosciences, Frederick, MD). The protocol for the First Strand kit involves an additional genomic DNA elimination step followed by preparation of a reverse transcriptase cocktail and incubation of 10 $\mu \mathrm{L}$ at $42^{\circ} \mathrm{C}$ for $15 \mathrm{~min}$. The cDNA synthesis reaction was stopped by heating to $95^{\circ} \mathrm{C}$ for $5 \mathrm{~min}$. Nineteen microliters of water was added to the cDNA product and the solution was stored at $-20^{\circ} \mathrm{C}$ until further analysis.

cDNA was analyzed on the commercially available TLR Profiler Array using the supplied protocol. The protocol involved adding $102 \mu \mathrm{L}$ of cDNA reaction product to $1350 \mu \mathrm{L}$ of supplied SABiosciences $\mathrm{RT}^{2}$ qPCR Master Mix and bringing the volume up to $2700 \mu \mathrm{L}$ with water. Twenty-five microlitres of this experimental cocktail was added to each well on the 96-well plate, which was then loaded in an ABI 7900HT Fast RT-PCR system (Applied Biosystems Inc., Foster City, CA) and run in a two-step cycling program with one initial cycle of $95^{\circ} \mathrm{C}$ for $10 \mathrm{~min}$ and 40 cycles of $15 \mathrm{~s}$ at $95^{\circ} \mathrm{C}$ and $1 \mathrm{~min}$ at $60^{\circ} \mathrm{C}$. Each sample was tested once with these arrays.

Sample normalization. The cycle threshold $\left(C_{\mathrm{t}}\right)$ for the housekeeping gene beta actin (ACTB) was determined on each array. The relative expression of each TLR-related gene $\left(C_{\mathrm{t}}\right.$ Exp) was normalized with ACTB by subtracting the latter from the former. Because the level of gene expression is inversely proportional to the $C_{\mathrm{t}}$ and the amount of product doubles with each cycle of the RT-PCR, the value $\Delta C_{\mathrm{t}}$ is converted to the gene expression level by raising 2 to the negative $\Delta C_{\mathrm{t}}\left(2^{-} \Delta C_{\mathrm{t}}\right)$. This protocol provided a $C_{\mathrm{t}}$ value for each well corresponding to the relative expression levels of the mRNA of 84 TLR-mediated signal transduction pathway genes for each sample. Data from one sample were not used because the expression of the housekeeping genes was significantly anomalous indicating a processing error on the entire array.

Array data analysis. The data for the 84 TLR pathway-related genes were analyzed by linear regression with estimated GA related to ACTB normalized expression levels using JMP 8 (SAS, Cary, NC). The $p$ values for slope of each gene's regression line were organized and processed with a false discovery rate algorithm with a detection rate of $10 \%$. The use of the false detection rate identifies genes likely to be developmentally expressed and, therefore, meriting further investigation.

Expression data for both TLR2 and TLR4 specifically were analyzed by pooling the 23 samples into three groups based on estimated GA corresponding approximately to different stages of organogenesis. Samples were organized around 60 (57-59 d), 90 (89-91 d), and 130 (117-154 d) d, representing the early and late pseudoglandular stages and the canalicular stage of lung development, respectively. Median expression levels for both TLR2 and TLR4 for each group were compared with Kruskal-Wallis analysis of variance using SPSS 17.0 (SPSS Inc., Chicago, IL).

RNA TaqMan analysis. To confirm and expand on the TLR2 findings in the first stage of this research, we analyzed extracted total RNA from 133 human fetal lung tissue samples with a TLR2 RT-PCR TaqMan assay and normalized to $18 \mathrm{~S}$ ribosomal RNA (TaqMan ribosomal RNA Control Reagents; Applied Biosystems, Foster City, CA). This experimental protocol included a one-step reverse transcriptase reaction before the RT-PCR. We used the same tissue population described above. After determining the RNA concentration on a Nanodrop instrument (Thermo Scientific, Waltham, MA), each sample was diluted to $5 \mu \mathrm{g} / \mu \mathrm{L}$ and mixed with $5 \mu \mathrm{L}$ of Master Mix without UNG, $0.25 \mu \mathrm{L}$ of Multiscribe and RNase inhibitor mix, $0.5 \mu \mathrm{L}$ of TLR2 gene assay $20 \times$ mix, and $1.25 \mu \mathrm{L}$ of water. Three microliter of RNA solution was added to this $7 \mu \mathrm{L}$ of TaqMan reaction mix for a total reaction volume of $10 \mu \mathrm{L}$. On each 96 well plate, 18 samples were loaded in triplicate reactions with a cDNA standard $\left(10^{7}-10^{2}\right.$ molecules $)$ and nontemplate controls. The TLR2 RNA content of each lung tissue sample was analyzed using the Applied Biosystems (Foster City, CA) TaqMan RNA-to-CT 1-Step Kit and a TLR2 TaqMan gene expression assays. The cycler protocol involved an initial reverse transcriptase step $\left(30 \mathrm{~min}\right.$ at $50^{\circ} \mathrm{C}$ and then $10 \mathrm{~min}$ at $95^{\circ} \mathrm{C}$ ) followed by 40 cycles of RT-PCR $\left(15 \mathrm{~s}\right.$ at $95^{\circ} \mathrm{C}$ and 1 minute at $\left.60^{\circ} \mathrm{C}\right)$. The $18 \mathrm{~S}$ rRNA was measured in each sample in triplicate reactions and compared with an $18 \mathrm{~S}$ rRNA cDNA standard $\left(10^{8}-10^{3}\right.$ molecules) using the TaqMan Ribosomal RNA Control Reagents in an ABI 7900HT Fast RT-PCR system (Applied Biosystems, Foster City, CA) according to the manufacturer's recommendations. We obtained a value for the relative amount of each sample by using the slope of the logarithmic curve for the standard run on each plate and the mean $C_{\mathrm{t}}$ for each experimental RNA sample. These values were then normalized using the mean $C_{\mathrm{t}}$ for each corresponding $18 \mathrm{~S}$ rRNA. A regression analysis was then performed relating estimated GA with TLR2 gene expression using both a linear and logarithmic trendline and with corresponding ANOVA tables using Microsoft Excel 2003 (Microsoft, Redmond, WA).

\section{RESULTS}

Plate array analysis. Analysis of all 84 TLR-related genes using a false detection rate of $10 \%$ was performed on the $p$ values for the slope of the regression line and revealed 32 genes that were differentially expressed (Table 1). Five of the identified genes were down-regulated from the $60 \mathrm{~d}$ group to the $130 \mathrm{~d}$ group including IL- $1 \alpha$ and its associated kinase 1, whereas 27 genes were found to be up-regulated over the period studied including TLR2, 3, 5, 6, 7, 8, and 10 as well as IL-8 and IL- $1 \alpha$-associated kinase 2 .

TLR2 and TLR4 pooled median analysis. Analyzing the pooled sample means of TLR2 and TLR4 from the three pooled age groups revealed similar normalized relative gene expression $($ TLR $2=0.000777$ and TLR $4=0.00112$, respectively) in the $60 \mathrm{~d}$ group (57-59 d). Setting the expression level in this youngest group arbitrarily to 1 , we then calculated the fold change for the subsequent groups. When compared with the 60-d pooled samples, median TLR2 expression showed a 3.9-fold increase in the $90 \mathrm{~d}$ group (89-91 d) and a 9.2-fold increase in the $130 \mathrm{~d}$ group (117-154 d; Fig. 1; $p<$ 0.001). Data reported reflect normalization with the ACTB housekeeping gene. We normalized the data with housekeeping genes hypoxanthine phosphoribosyltransferase 1 and beta2-microglobulin and the findings were preserved independent of the normalizing gene used (data not shown). TLR4 expression remained low and was not different among the three groups ( $p=0.949$; Fig. 1$)$.

TLR2 TaqMan analysis. The expanded results $(n=133$ samples) for TLR2 using the TaqMan assay with expression normalized with $18 \mathrm{~S}$ ribosomal RNA for each sample were plotted against estimated GA (Fig. 2). Analysis with linear regression confirmed the developmental expression. The natural logarithm of the TLR2 expression plotted against age of the samples provides a best-fit line with an $R^{2}=0.359$ and $p<0.001$ indicating an exponential increase over the time studied of the TLR2 gene.

\section{DISCUSSION}

By using a false detection rate algorithm, we identified 32 TLR signaling pathway genes that seem to be developmentally regulated in developing prefunctional lung. Five of these 32 genes seemed to be down-regulated during the period of investigation, whereas there was coordinated up-regulation of 
Table 1. TLR signaling pathway genes with identified developmental expression

\begin{tabular}{|c|c|}
\hline Gene & $\begin{array}{l}\text { Fold increase in } \\
130 \mathrm{~d} \text { group }\end{array}$ \\
\hline IL-8 & 10.34 \\
\hline $\begin{array}{l}\text { Colony stimulating factor } 2 \\
\quad \text { (granulocyte-macrophage) }\end{array}$ & 10.19 \\
\hline Toll-like receptor 2 & 9.20 \\
\hline Chemokine (C-X-C motif) ligand 10 & 7.28 \\
\hline $\begin{array}{l}\text { IL-12A (natural killer cell stimulatory } \\
\text { factor } 1 \text {, cytotoxic lymphocyte } \\
\text { maturation factor } 1, \mathrm{p} 35 \text { ) }\end{array}$ & 4.59 \\
\hline Toll-like receptor 1 & 4.13 \\
\hline Toll-like receptor 10 & 4.06 \\
\hline IL-1 receptor-associated kinase 2 & 3.96 \\
\hline Toll-like receptor 8 & 3.93 \\
\hline Chemokine (C-C motif) ligand 2 & 3.26 \\
\hline $\begin{array}{l}\text { Nuclear factor of kappa light polypeptide } \\
\text { gene enhancer in B-cells inhibitor, } \\
\text { alpha }\end{array}$ & 3.11 \\
\hline ECSIT homolog (drosophila) & 3.07 \\
\hline TANK-binding kinase 1 & 2.94 \\
\hline Toll-like receptor adaptor molecule 1 & 2.91 \\
\hline Heat shock $70 \mathrm{kDa}$ protein $1 \mathrm{~A}$ & 2.48 \\
\hline Toll-like receptor 7 & 2.37 \\
\hline Interferon regulatory factor 1 & 2.28 \\
\hline Lymphocyte antigen 86 & 2.19 \\
\hline Toll-like receptor 6 & 2.07 \\
\hline CD86 molecule & 1.86 \\
\hline Toll-like receptor 5 & 1.85 \\
\hline Toll-like receptor adaptor molecule 1 & 1.77 \\
\hline $\begin{array}{l}\text { Nuclear factor of kappa light polypeptide } \\
\text { gene enhancer in B-cells } 1 \text { (p105) }\end{array}$ & 1.75 \\
\hline $\begin{array}{l}\text { Caspase } 8 \text {, apoptosis-related cysteine } \\
\text { peptidase }\end{array}$ & 1.47 \\
\hline $\begin{array}{l}\text { Receptor-interacting serine-threonine } \\
\text { kinase } 2\end{array}$ & 1.47 \\
\hline Toll-like receptor 3 & 1.43 \\
\hline Lymphocyte antigen 96 & 1.42 \\
\hline $\begin{array}{l}\text { Ubiquitin-conjugating enzyme E2N } \\
\text { (UBC13 homolog, yeast)* }\end{array}$ & 0.85 \\
\hline $\begin{array}{l}\text { Conserved helix-loop-helix ubiquitous } \\
\text { kinase* }\end{array}$ & 0.72 \\
\hline IL-1 receptor-associated kinase $1 *$ & 0.53 \\
\hline IL-1, alpha* & 0.51 \\
\hline High-mobility group box $1 *$ & 0.49 \\
\hline
\end{tabular}

Genes identified with a $10 \%$ false detection rate as displaying developmental regulation with their fold change from the $60 \mathrm{~d}$ group (expression set to 1) to the $130 \mathrm{~d}$.

* Genes with decreased expression over three stages of development.

27 genes (Table 1). The lung tissues studied were at stages of development at which gas exchange and exposure to external environment are not occurring rendering it unlikely that a direct interface for infection would be present as a stimulus for up-regulation. Among the up-regulated genes, TLR2, colony stimulating factor 2 and IL-8 had among the highest fold increases. TLR4 was found in the 60-d lung samples at a concentration comparable with TLR2; however, there was no change in the TLR4 expression level with increasing GA. TLR2 activation results in expression of IL-8 in B-cells (15). However, the tissue samples studied are presumed to be derived from elective terminations of pregnancy and, as such, are assumed to have been evacuated from a noninflamed milieu. TLR 2 can be triggered by endogenous ligands and has

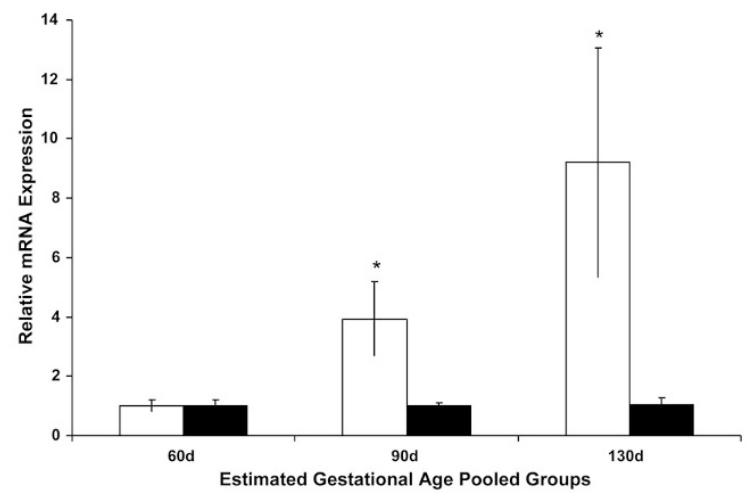

Figure 1. TLR fold increase in human fetal lung. Expression levels of TLR2

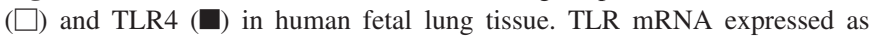
relative values with value of the mean of the $60 \mathrm{~d}$ group set to one. The $95 \%$ confidence interval bars shown. TLR2 expression is significantly different in the 90 and $120 \mathrm{~d}$ groups compared with the $60 \mathrm{~d}$ group $(p<0.001)$ while TLR4 is unchanged $(p=0.906)$.

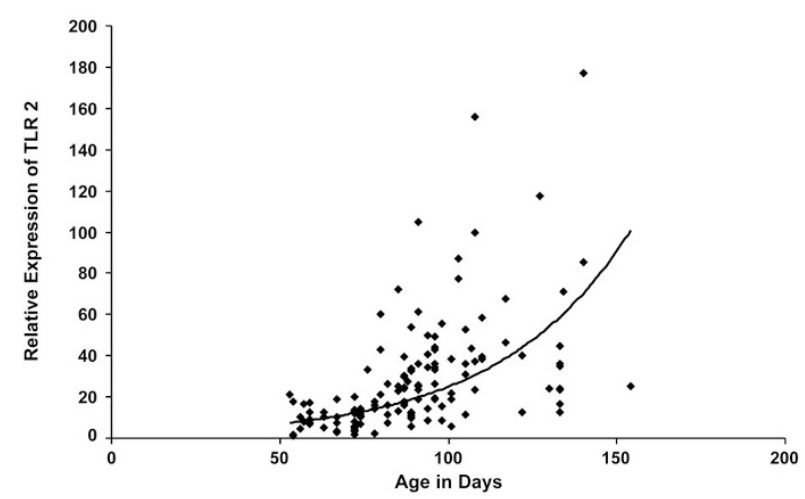

Figure 2. TLR2 expression with increasing GA. Plot of TLR2 expression in 133 fetal lung samples $v s$ estimated GA. Best-fit exponential curve is shown $(y=1.9021 \mathrm{e} 0.0258 x) . R^{2}=0.359$ and $p<0.001$.

been shown to lead to IL-8 stimulation in both gingival and renal epithelial cells $(16,17)$. Thus, the coordinated and proportional up-regulation could imply translation of the detected TLR2 mRNA to functional protein or indicate a developmental function of IL-8 in addition to TLR2. The identified genes displaying developmental expression provide candidates for further investigation of the interplay of the TLR cascade during pulmonary development.

We confirmed a developmental up-regulation of TLR2 gene expression in human fetal lung tissue during the period of development from the early pseudoglandular stage through the late pseudoglandular and the canalicular stages. Although the curve of best-fit for TLR2 expression was exponential for the period studied, the levels of TLR2 mRNA in the canalicular stage were approximately equal to two adult samples tested (data not shown). This is the first description of human fetal lung expression of TLR signaling pathway genes.

The full role of TLRs in fetal development is still evolving. There are suggestions of nonimmune developmental functions of TLRs from the preservation of tissue architecture by TLR4 in mice (11) to the emerging role of TLR8 in normal neurite development (18). TLRs have been found to be expressed on nonimmune pulmonary cells in both sheep and rabbits $(13,19)$, 
and TLR2 has been shown to lead to the production of IL-8 from epithelial cells in renal and gingival cells. The differing patterns of our TLR2 and TLR4 expression from published ovine and murine studies $(12,13)$ caution against overgeneralization of animal TLR studies to humans. Thus, although the role of TLRs in human fetal lung development is unknown, the increased expression of TLR2 occurring in the late pseudoglandular and canalicular stages of development suggests a possible novel developmental function.

There are several limitation to our study including a lack of staining of the samples to indicate the cell types expressing TLRs within the lung homogenate and in the inability to test samples closer to viability and on to term gestation. A further limitation of this study is the assumption that lung samples were otherwise normally developing fetuses, although we have no means for independent confirmation.

In conclusion, TLR2, but not TLR4, is developmentally expressed during lung development before the ability of gas exchange. This pattern of expression stands in contrast to similar animal studies and suggests a role of TLR2 in human lung organogenesis.

Acknowledgment. We thank Drs. Howard Kilbride and Jason Newland for critical reading of this article.

\section{REFERENCES}

1. Fusunyan RD, Nanthakumar NN, Baldeon ME, Walker WA 2001 Evidence for an innate immune response in the immature human intestine: toll-like receptors on fetal enterocytes. Pediatr Res 49:589-593

2. Basu S, Fenton MJ 2004 Toll-like receptors: function and roles in lung disease. Am J Physiol Lung Cell Mol Physiol 286:L887-L892
3. Chaudhuri N, Whyte MK, Sabroe I 2007 Reducing the toll of inflammatory lung disease. Chest 131:1550-1556

4. Raymond T, Schaller M, Hogaboam CM, Lukacs NW, Rochford R, Kunkel SL 2007 Toll-like receptors, Notch ligands and cytokines drive the chronicity of lung inflammation. Proc Am Thorac Soc 4:635-641

5. Krediet TG, Wiertsema SP, Vossers MJ, Hoeks S, Fleer A, Ruven H, Rijkers GT 2007 Toll-like receptor 2 polymorphism is associated with preterm birth. Pediatr Res 62:474-476

6. Abreu MT, Arditi M 2004 Innate immunity and Toll-like receptors: clinical implications of basic science research. J Pediatr 144:421-429

7. Sadeghi K, Berger A, Langgartner M, Prusa A, Hayde M, Herkner K, Pollak A, Spittler A, Forster-Waldl E 2007 Immaturity of infection control in preterm and term newborns is associated with impaired toll-like receptor signaling. J Infect Dis 195:296-302

8. Viemann D, Dubbel G, Schleifenbaum S, Harms E, Sorg C, Roth J 2005 Expression of toll-like receptors in neonatal sepsis. Pediatr Res 58:654-659

9. Noakes PS, Hale J, Thomas R, Lane C, Devadason SG, Prescott SL 2006 Maternal smoking is associated with impaired neonatal toll-like-receptor-mediated immune responses. Eur Respir J 28:721-729

10. Fleer A, Krediet TG 2007 Innate immunity: toll-like receptors and some more Neonatology 92:145-157

11. Willet KE, Jobe AH, Ikegami M, Newnham J, Brennan S, Sly PD 2000 Antenatal endotoxin and glucocorticoid effects on lung morphometry in preterm lambs. Pediatr Res 48:782-788

12. Harju K, Glumoff V, Hallman M 2001 Ontogeny of toll-like receptors Tlr2 and Tlr4 in mice. Pediatr Res 49:81-83

13. Hillman NH, Moss TJ, Nitsos I, Kramer BW, Bachurski CJ, Ikegami M, Jobe AH, Kallapur S 2008 Toll-like receptors and agonist responses in the developing fetal sheep lung. Pediatr Res 63:388-393

14. Zhang X, Shan P, Jiang G, Cohn L, Lee PJ 2006 Toll-like receptor 4 deficiency causes pulmonary emphysema. J Clin Invest 116:3050-3059

15. Jagannathan M, Hasturk H, Liang Y, Shin H, Hetzel JT, Kantarci A, Rubin D, McDonell ME, VanDyke TE, Ganley-Leal LM, Nikolajczyk BS 2009 TLR crosstalk specifically regulates cytokine production by B cells from chronic inflammatory disease patients. J Immunol 183:7461-7470

16. Eskan MA, Hajishengallis G, Kinane DF 2007 Differential activation of human gingival epithelial cells and monocytes by Porphyromona gingivalis fimbriae. Infect Immun 75:892-898

17. Chowdhury P, Sacks SH, Sheerin NS 2006 Toll-like receptors TLR2 and TLR4 initiate the innate immune response of the renal tubular epithelium to bacterial products. Clin Exp Immunol 145:346-356

18. Ma Y, Li J, Chiu I, Wang Y, Sloane JA, Lu J, Kosaras B, Sidman RL, Volpe JJ, Vartanian T 2006 Toll-like receptor 8 functions as a negative regulator of neurite outgrowth and inducer of neuronal apoptosis. J Cell Biol 175:209-215

19. Martin TR, Frevert CW 2005 Innate immunity in the lungs. Proc Am Thorac Soc 2:403-411 